\title{
Giá trị công ích của bình duyệt khoa học
}

\author{
Hồ Mạnh Toàn
}

SSHPA System

\author{
E-mail: toan@sshpa.com
}

Hà Nội, 27-11-2018

\section{Công ích khoa học và phản biện}

Công việc học thuật thường được chia thành 3 phần chính: giảng dạy, nghiên cứu, và phục vụ cộng đồng. Nếu như hai vế đầu khá dễ hiểu thì phần phục vụ cộng đồng lại là câu chuyện không phải ai cũng biết. Với nghề học thuật, phục vụ cộng đồng có thể bao gồm nhiều hoạt động như: góp ý, phân tích chính sách; tham gia các hội đồng đánh giá chuyên môn; bình duyệt khoa học .... Trong khuôn khổ bài viết, tác giả sẽ thảo luận về hoạt động bình duyệt khoa học cũng như phân tích những xu hướng mới cuả hoạt động công ích này.

Trong công bố khoa học, một bản thảo sau khi được nộp thành công đến một tạp chí sẽ trải qua các giai giai đoạn chính sau đây:

(i) thẩm định sơ bộ của ban biện tập;

(ii) gửi bài cho các nhà khoa học có cùng chuyên môn để bình duyệt (phổ biến là bình duyệt kín, tức là người bình duyệt và người viết bài không biết rõ nhau do danh tính đã được ban biên tập giấu đi, nhất là doubleblind);

(iii) nhận kết quả bình duyệt và chỉnh sửa;

(iv) công trình khoa học được công bố.

Trong 4 bước kể trên, trong nhiều trường hợp bước (ii) và (iii) phải lặp đi lặp lại 2-3 vòng trước khi người bình duyệt thông qua và chuyển sang bước (iv). Điều này khiến cho tổng thời gian của quá trình bình duyệt kéo dài vài tháng, cá biệt có thể lên đến 1-2 năm, trước khi được chấp nhận và công bố chính thức.

Như vậy, ở đây, các nhà bình duyệt đã đóng vai trò quan trọng nhất trong toàn bộ chu trình xuất bản khoa học: chốt chặn kiểm tra chất lượng và nắm giữ số phận bản thảo. Và hẳn nhiên đây cũng là việc mệt nhọc và tốn thời gian. Trong một bài phỏng vấn trên Nature [1], Malcolm Jobling - một nhà khảo học - chia sẻ rằng ông có thể phải bình duyệt khoảng 100 bản thảo 1 năm, với khoảng thời gian từ 3 đến 12 
tiếng cho một bản thảo. Như vậy, trong một năm, Jobling có thể phải dành tới hàng trăm, thậm chí cả nghìn giờ cho riêng việc này, chưa kể vẫn phải đảm bảo hai công việc khác là giảng dạy và nghiên cứu khoa học. Điều đáng nói nữa, việc bình duyệt này, về mặt truyền thống là hoàn toàn ẩn danh và thầm lặng, nó khác hoàn toàn công việc quản lý ồn ào và hào nhoáng hơn nhiều.

\section{Giá trị của phản biện là gì?}

Trong giới khoa học, bình duyệt hiện tại được xem là cách hữu hiệu nhất để đảm bảo sự trong sạch của tri thức. Đồng thời, bình duyệt cũng là quá trình giúp người làm bình duyệt rèn luyện, cọ xát, kiểm tra nền tảng kiến thức chuyên môn của chính bản thân họ. Tự rèn luyện, đào tạo bản thân và cống hiến chính là một trong những phẩm chất đáng quý của mà người lao động nào cũng cần có.

Chính vì thế, việc tham gia bình duyệt là một cách để xây dựng thương hiệu và uy tín học thuật cho nhà khoa học. Sau khi vượt qua các mức sàn về sản lượng, năng suất công bố khoa học, vinh dự được ban biên tập trao cho quyền đánh giá nghiên cứu mới của đồng nghiệp là một lời mời có giá trị xác nhận vị thế chuyên gia trong ngành của nhà khoa học.

Cuối cùng, sự kết nối rộng khắp thông qua bình duyệt chính là vẻ đẹp của khoa học hiện đại. Ví dụ, khi một nhà khoa học tại Việt Nam có thể bình duyệt một bản thảo của một tác giả Mỹ, công việc công ích đấy hoàn toàn có thể là khởi đầu cho những hợp tác mới khác. Thông qua công nghệ, khoa học ngày một mở hơn, và toàn cầu hóa hơn. Vì thế, việc tham gia vào các công việc công ích khoa học và bình duyệt giúp nhà khoa học có thể hiểu thêm về các ngóc nghách của nghề nghiên cứu. Sự thấu hiểu nghề nghiệp đó sẽ giúp các nhà khoa học tự chủ hơn trong công việc của mình: biết thêm nhiều nhà khoa học mới, hiểu thêm về cách làm việc của hệ thống.

Cũng như mọi ngành, lĩnh vực khác, khoa học hiện tại cũng đang có những bước chuyển mình hướng đến minh bạch hóa hơn, với những lời kêu gọi dữ liệu mở, đối thoại mở và cả bình duyệt "mở" (tức là người bình duyệt và tác giả biết danh tính của nhau) [2,3]. Sự ra đời của tạp chí mở hoàn toàn F1000Research cách đây vài năm phản ánh xu hướng đó. Đã có một số tác giả Việt Nam công bố trên tạp chí này và người đọc có thể xem đầy đủ biên bản phản biện và trả lời của các tác giả ${ }^{[4,5]}$. Xu hướng này mang đến những giá trị mới cho công ích khoa học và giúp việc đánh giá uy tín học thuật toàn diện hơn về mọi mặt.

\section{Hệ thống Publons và một bước tiến mới của phản biện khoa học}


Trước Publons ra mắt vào năm 2013, thói quen chung của giới khoa học đều là bình duyệt ẩn danh. Công sức của các nhà bình duyệt thường được ghi nhận qua vài dòng cảm ơn trong bài được đăng, hoặc trong lời cảm ơn từ ban biên tập, hoặc đối với các nhà bình duyệt năng suất cao, phần thưởng có thể là vị trí trong ban biên tập của của tạp chí. Vấn đề trả công hiếm khi được đề cập đến trong phản biện vì tính chất nhạy cảm đạo đức khoa học của nó. Vì vậy, bình duyệt vẫn thường nằm bên lề khoa học. Đôi lúc, công việc này cũng được vinh danh nhưng lại theo cách chả giống ai như một khối bê tông tại trường ĐH Kinh tế Nga (Higher School of Economics) đã được kêu gọi góp vốn cộng đồng trên Kickstarter để biến nó thành một tượng đài dành cho các nhà bình duyệt ẩn danh đầu tiên trên thế giới [6]. Sự ra đời của hệ thống Publons mang đến một làn gió mới ghi nhận đóng góp của các phản biện một cách hệ thống và chính thống hơn.

Publons được sáng lập bởi Preston và Johnston với mục đích kết nối bốn nhóm quan trọng trong giới khoa học: Nhà xuất bản-Tác giả-Người bình duyệt-Các tổ chức khoa học. Hệ thống tạo lập một cơ sở dữ liệu (CSDL) xuyên suốt từ hồ sơ người bình duyệt, dữ liệu bài vở để xử lí và thống kê về năng suất lao động và mức đóng góp trung bình của các người bình duyệt. Hệ thống Publons hiện nay kết nối với hơn 500.000 người bình duyệt, khoảng 3 triệu bản ghi đã xác minh và hơn 25.000 tạp chí đã đăng kí với hệ thống. Các nhà bình duyệt đăng kí và lưu trữ hồ sơ của mình trên Publons sẽ được tính điểm dựa trên hồ sơ và hàng năm kể từ 2016, giải thưởng Publons Peer Review Awards sẽ được trao cho những nhà bình duyệt xuất sắc nhất.

Theo CSDL Publons, nhà bình duyệt năng suất nhất của Việt Nam hoàn thành được 77 báo cáo phản biện một năm. Trong khi đó, nhà bình duyệt năng suất tốp đầu một năm của Indonesia là 369 bài, Singapore là 196 bài, và Thái Lan với 178 bài. Tuy vậy, bình duyệt khoa học Việt Nam cũng có những điểm sáng đáng khích lệ như trong khối ngành khoa học xã hội đã có đại diện xuất hiện trong nhóm dẫn đầu. Điều đó cho thấy, bình duyệt là một hướng đi cụ thể tiếp theo để phát triển uy tín học thuật của nước nhà.

Đối với giới khoa học quốc tế, sự ra đời của Publons và giải thưởng như Publons Peer Review Awards, cùng với lời kêu gọi open-access trong xuất bản học thuật dự báo sẽ mở ra một thời kì mới trong khoa học. Trong khi đó, tại Việt Nam, công bố quốc tế và nghiên cứu khoa học vẫn còn là các khái niệm đang được cập nhật với các tiêu chuẩn toàn cầu và các vấn đề về chi phí học thuật cũng cần có sự xem xét kĩ càng [7]. Vì thế, bình duyệt, và ngay cả nghiên cứu khoa học, chắc chắn sẽ cần thêm thời gian để trở nên quen thuộc với đại chúng.

Thực ra, công việc bình duyệt mở này không phải quá mới nếu ta nhìn rộng ra. Ví dụ, năm 1966, Hiệp hội Bình luận phim Quốc gia (National Society of Film 
Critics) của Hoa Kỳ ra đời, đánh dấu một thời kì mới của phê bình điện ảnh tại xứ cờ hoa với hai trường phái Báo chí và Hàn lâm - một nhằm định hướng khán giả, và một có có mục tiêu nghiên cứu.

Hiệp hội này cũng lập ra các giải thưởng uy tín dành cho giới bình luận Mỹ hàng năm. Ngay cả các hoạt động thẩm định, đánh giá cũng trong kinh tế hay giáo dục cũng đều có tính chất tương tự công việc bình duyệt khoa học. Các nhà khoa học đầu ngành vẫn thường xuyên đóng góp phản biện xã hội thông qua truyền thông đại chúng. Tuy nhiên, xã hội vẫn còn có nhiều câu hỏi hay định kiến về công việc khoa học. Ngay cả đối với xã hội Mỹ, theo một báo cáo mới đây của Viện Hàn Lâm Khoa học và Nghệ thuật Mỹ (American Academy of Arts \& Sciences), câu hỏi về khác biệt "nghiên cứu khoa học" với "phát kiến và tiến bộ khoa học" vẫn làm cho hơn $50 \%$ số người được hỏi không thể trả lời.

Vì thế, xã hội hiểu thêm về công việc của các nhà nghiên cứu chính là bước đầu để xã hội rộng rãi và giới học thuật có thể tìm thấy điểm giao thoa, tiến tới học hỏi hay hợp tác lẫn nhau. Sự học hỏi qua lại này còn tạo ra cơ hội củng cố năng lực hỗ trợ tiến bộ qua hiện tượng phổ biến trong khoa học là "serendipity" mà nói như Pablo Picasso: "Je ne cherche pas, je trouve" [8,9].

\section{References:}

[1] Noorden, R. V. (2014). The scientists who get credit for peer review. Nature, DOI:10.1038/nature.2014.16102.

[2] Vuong, Q. H. (2017). Open data, open review and open dialogue in making social sciences plausible. Nature: Scientific Data Updates. Retrieved from http://blogs.nature.com/scientificdata/2017/12/12/authors-corner-opendata-open-review-and-open-dialogue-in-making-social-sciences-plausible/.

[3] Polka, J. K., Kiley, R., Konforti, B., Stern, B., \& Vale, R. D. (2018). Publish peer reviews. Nature, 560, 545-547, doi:10.1038/d41586-018-06032-w.

[4] Ho, T. M., Nguyen, H. V., Vuong, T. T., Dam, Q. M., Pham, H. H., \& Vuong, Q. H. (2017). Exploring Vietnamese co-authorship patterns in social sciences with basic network measures of 2008-2017 Scopus data. F1000Research, 6, 1559, DOI: 10.12688/f1000research.12404.1.

[5] Nguyen, H. V., Trinh, N. B., Le, H. T., Nguyen, C. T., Mai, H. T., Tran, T. D., ... \& Vu, T. T. M. (2017). Preference and willingness to pay for nutritional counseling services in urban Hanoi. F1000Research, 6, 233, DOI: 10.12688/f1000research.10974.2. 
[6] Schiermeier, Q. (2017). Monument to peer review unveiled in Moscow. Nature, DOI: 10.1038/nature.2017.22060. Available from URL: https://www.nature.com/news/monument-to-peer-review-unveiled-in$\underline{\text { moscow- } 1.22060}$

[7] Vuong, Q. H. (2018). The (ir)rational consideration of the cost of science in transition economies. Nature Human Behaviour, 2(1), 5. Available from URL: https://www.nature.com/articles/s41562-017-0281-4.

[8] Napier, N. K., \& Vuong, Q. H. (2013) Serendipity as a strategic advantage?. In Wilkinson (ed.) Strategic Management in the 21st Century (pp. 175-199). Westport, CT: Praeger.

[9] Ott, L. (2013). Travail Social, les Raisons d'Agir. Paris, France: ERES. 